\title{
MOTIONS OF RIGID BODIES AND CRITERIA FOR OVERTURNING BY EARTHQUAKE EXCITATIONS
}

\author{
Yuji Ishiyama* \\ Presented at the Third South Pacific Regional Conference on \\ Earthquake Engineering, Wellington, May 1983.
}

\section{SYNOPSIS :}

This investigation deals with motions of rigid bodies on a rigid floor subjected to sinusoidal and earthquake excitations, and overturning of the bodies. Experiments and simulations of frequency sweep tests were conducted, and it is concluded that the horizontal velocity as well as the acceleration must be taken into account as criteria for overturning. Simulations by earthquake excitations show that the criteria are also applicable to the earthquake excitations. Therefore it is possible to estimate the lower limits of the maximum horizontal acceleration and velocity of the input excitations, from the overturning of bodies.

\section{INTRODUCTION :}

Despite their familiarity and apparent simplicity, the motions and overturning of rigid bodies in response to earthquake excitations pose extremely difficult problems when exact solutions are sought. Subsequent to the pioneering works of Milne (1) and Perry (2), both of which were disclosed in 1881, the behaviour of rigid bodies during earthquakes has intrigued a number of seismologists and earthquake engineers for over a hundred years as has been noted by the present author (3). These interests have been mainly motivated by the possibility of estimating the peak acceleration of earthquake excitations at sites for which no seismographic records are available. Typical examples are the contributions of Japanese researchers to the estimation of seismic intensities by observing the overturning of tombstones in the graveyards. (4-7) Another promising aspect of this type of study, which has attracted the attention of many researchers in recent years, (8-9) is its applicability to preventing building furniture and equipment from overturning when exposed to shaking during earthquakes.

The most common procedure used to estimate the seismic intensity at the site is to assume that the peak acceleration was larger than the breadth-height-ratio of an overturned body multiplied by the gravitational acceleration, as represented by West's formula. (10) But this criterion shows only the condition which initiates rocking motion and does not indicate a condition sufficient to overturn a body, even if the vertical acceleration is considered. (11) In order to analyze the motions of a body, many researchers assume that the body rotates about either of the base edges, which then alternately become the center of rotation after impact between the body and the floor, and also that the angular momentum is conserved at the instant of impact, neglecting the effecfs of restitution and friction. $(12,13)$ For the

Head, Building Engineering Division, International Institute of Seismology and Earthquake Engineering, Building Research Institute, Ministry of Construction first time Ohtsuki and Kanai(14) theoretically analyzed the motions after impact from rocking motion, considering the effect of restitution. (15pllowing them, Mochizuki and Kobayashi (15) studies the four types of motion of a body (i.e. slip, rocking, rocking-slip and jump); transitions between the types of motion. and the motions after impact. But they used the assumption that the restitution coefficient is the ratio between the velocities just after and just before impact. This assumption is applicable only if the tangent impulse is neglected.

In this paper, motions of a rigid body in response to earthquake excitations are theoretically studied, using the computer simulation program which classifies the types of motion into six (rest, slide, rotation, slide rotation, translation jump and rotation jump). Several types of simulations were conducted so that the characteristics of motions and overturning of bodies are studied. Criteria for the overturning of bodies are proposed after experiments and simulations of frequency sweep tests. Simulations by earthquake excitations show that the criteria are also applicable to earthquake excitations. Therefore we can estimate the lower limits of the maximum horizontal acceleration and velocity of the input excitations from the overturning of bodies.

\section{COMPUTER SIMULATION PROGRAM:}

When a body on a floor is subjected to earthquake excitations, the body may remain at rest while the excitations are not large. When the excitations become large enough the body may rock, slide, jump or may undergo some combination of these motions. The computer program, which has been developed by the present author, $(16,17)$ can deal with any plane motions of a rigid body on a rigid floor subjected to the horizontal and vertical excitations. In the program, the motions are classified into six categories; i.e. (1) rest, (2) slide, (3) rotation, (4) slide rotation, (5) translation jump, and (6) rotation jump (See Fig. 1); and the equations of motion are solved numerically. Some applications of the program are shown in the following sections. The time step $\Delta t$ of the

BULLETIN OF THE NEW ZEALAND SOCIETY FOR EARTHQUAKE ENGINEERING, VOL. 17, NO. 1, MARCH 1984 
numerical integration is $1 / 1000 \mathrm{sec}$ except as indicated, but the successive positions of the body in Figs. $3-5$ are shown only every $1 / 50$ sec.

Simulations of Free Rocking:

If we tilt a body slightly and release it, the body starts rotating and it may continue rotation or it may transit into a slide rotation. After impact with the floor, the body undergoes one of the six types of motion explained in the previous paragraph. Simulations on this kind of motion which may be called free rocking have been carried out, changing the size of the body, coefficients of friction and restitution coefficients.

In the case that breadth-height-ratio $(\mathrm{b} / \mathrm{h}$, see Fig. 2) is not greater than surface and edge static coefficients of friction ( $\mu_{S}$ and $\left.\bar{\mu}_{S}\right)$, the body continues the rocking motion, repeating the impact between the body and the floor (See Fig. 3a; where $\mu_{\mathrm{k}}$ and $\bar{\mu}_{\mathrm{k}}$ are surface and edge kinetic coefficients of friction, respectively, and $e_{x}$ and $e_{y}$ are tangent and normal restitution coefficients, respectively). If $b / h$ becomes greater than $\mu_{s}$ and $\bar{\mu}_{S}$, the body slides to the reverse side of tilting after impact (See Figs. 3b, c). If $\mathrm{b} / \mathrm{h}$ becomes even greater still, the body undergoes slide rotation to the tilting side after rotation before impact and slides to the reverse side of tilting after impact (See Figs. 3d - g).

Considering the same size of a body, if $\mu_{\mathrm{S}}$ and $\bar{\mu}_{\mathrm{S}}$ are smaller than $\mathrm{b} / \mathrm{h}$, the body slides after impact and does not continue the rocking motion (see Fig. 4a). If $\mu_{s}$ and $\bar{\mu}_{s}$ are greater than $b / h$, the body continues the rocking motion, repearing the impact (See Fig. 4b). Therefore, in order for the rocking motion to continue, $\mu_{s}$ and $\bar{\mu}_{s}$ must be greater than $\mathrm{b} / \mathrm{h}$. The effects of $e_{x}$ and $e_{y}$ are not very large in the free rocking simulations.

Simulations of Motions after Translation Jump:

If we lift a body and release it with a certain value of horizontal velocity, the body may undergo various types of motion after impact. Simulations of this kind have been carried out with the following results.

If the horizontal impulse at the instant of impact is not taken into account or is very small $\left(e_{x} \simeq-1\right)$, the body slides in the direction of the initial horizontal velocity with repeated impacts (See Fig. 5a). If the horizontal impulse is large $\left(e_{x}>-1\right)$, the body tilts or overturns $x$ after the impact, depending on the values of the horizontal velocity, e $e^{\prime} e^{\prime}$ etc. (See Figs. $5 b-d)$. 'It is' interesting to note that the direction of overturning is not always the same. The direction of overturning can be in the same direction as the horizontal velocity or in the reverse direction (See Figs. 5c, d). Therefore it can be seen that the effects of $e$ and $e_{y}$ are very important in this kind of motion.

\section{REVIEW OF CRITERIA FOR OVERTURNING:}

Effects of Acceleration:

Milne ${ }^{(1)}$ introduced the horizontal acceleration "a" to initiate the rocking motion derived by west as follows:

$\mathrm{a}=\frac{\mathrm{b}}{\mathrm{h}} \mathrm{g}$

where $g$ is the gravitational acceleration. This is well-known as West's formula.

Mononobe (II) remarked that the vertical acceleration should be taken into account. Then the above formula becomes

$\frac{b}{h}=\frac{k_{x}}{1 \mp k_{y}}=k, K^{\prime}$

where $\mathrm{k}_{\mathrm{x}}$ and $\mathrm{k}_{\mathrm{y}}$ are the horizontal and vertical seismic coefficients. He called $K$ and $K^{\prime}$ the combined seismic coefficients. The above two formulae show the acceleration or seismic coefficient necessary to initiate rocking motion and not to overturn the body, as noted by Mononobe(11) and others.

Kirkpatrick (18) derived the following formula which determines the horizontal acceleration amplitude necessary to overturn a body by a half-cycle sine-pulse of duration $t_{1}$.

$a=\alpha g \sqrt{1+\frac{i^{2}+r^{2}}{g r}\left(\frac{\pi}{t_{1}}\right)^{2}}$

where $\alpha$ is the angle between the vertical line and the line from $O$ to $G$ of the body at rest, $i$ is the radius of gyration of the body about $G$ and $r$ is the distance from $O$ to $G$ (See Fig. 2). It should be noted, however, that this is derived on the assumption of a small $\alpha$.

If the excitation is a constant horizontal acceleration, the duration $t_{0}$ to overturn a body has the following

$$
\cosh \sqrt{\frac{g \alpha}{i^{2}+r^{2}}} t_{0}=I+\frac{1}{2 \frac{a}{g \alpha}\left(\frac{a}{g \alpha}-1\right)}
$$

This is also derived on the assumption of a small $\alpha$.

Effects of Velocity:

If the body is at rest, the increment of the potential energy PE per unit of mass to move the center of gravity just above the base edge is

$\mathrm{PE}=\mathrm{gr}(1-\cos \alpha)$

The kinetic energy $\mathrm{KE}$ of the body per unit of mass, which is rotating about its base edge and whose angular velocity is $\omega$, is given by

$$
\mathrm{KE}=\frac{1}{2}\left(i^{2}+r^{2}\right) \omega^{2}
$$




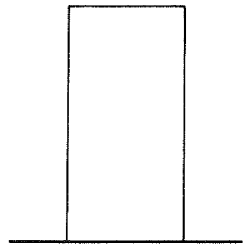

(1) Rest

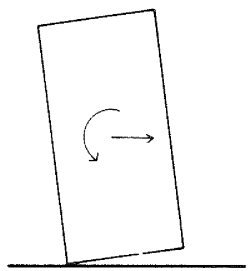

(4) Slide rotation

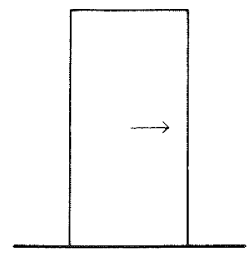

(2) Slide

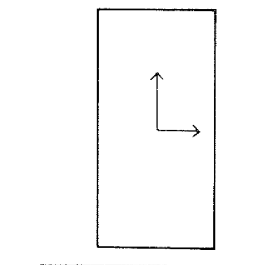

(5) Translation jump

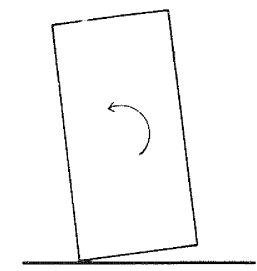

(3) Rotation

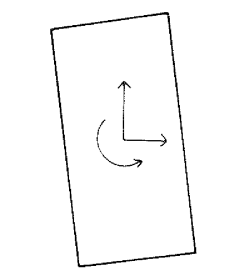

(6) Rotation jump

Fig.l Classifications of Motions of a Body
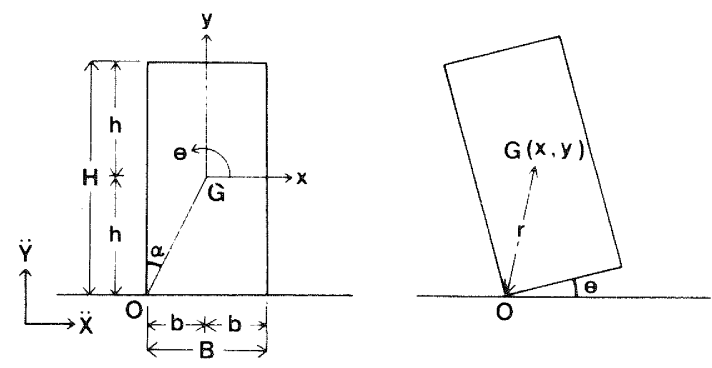

Fig.2 A Body in Motion

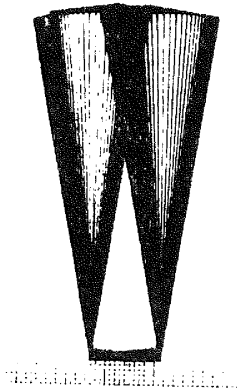

a. $b / h=1 / 5$

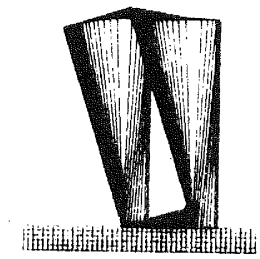

b. $\mathrm{b} / \mathrm{h}=1 / 3$
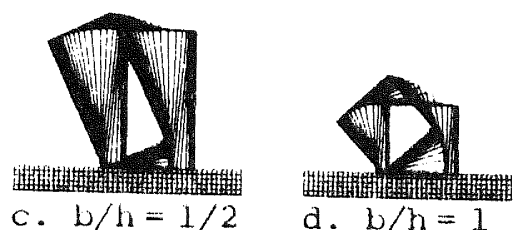

d. $\mathrm{b} / \mathrm{h}=1$

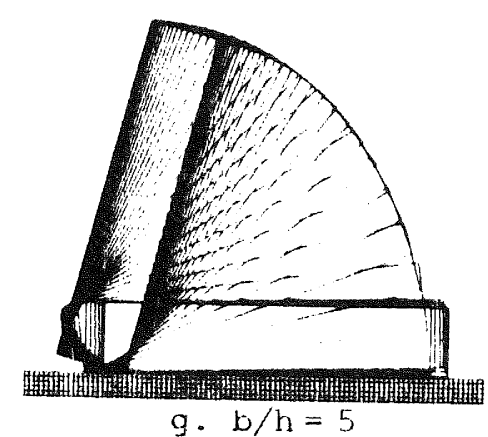

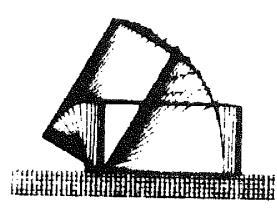

e. $b / h_{1}=2$

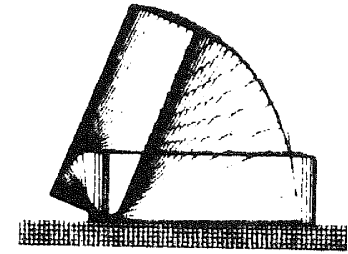

E. $b / h=3$ $\mathrm{g} \cdot \mathrm{b} / \mathrm{h}=5$

Fig. 3 Simulations of Eree Rocking - Effects of $\mathrm{b} / \mathrm{h}$ $\left(b=5 \mathrm{~cm}, \mu_{\mathrm{s}}=\bar{\mu}_{\mathrm{S}}=0.2, \mu_{\mathrm{k}}=\bar{\mu}_{\mathrm{k}}=0.15, \mathrm{e}_{\mathrm{x}}=-0.8, e_{\mathrm{y}}=0.2\right)$ 


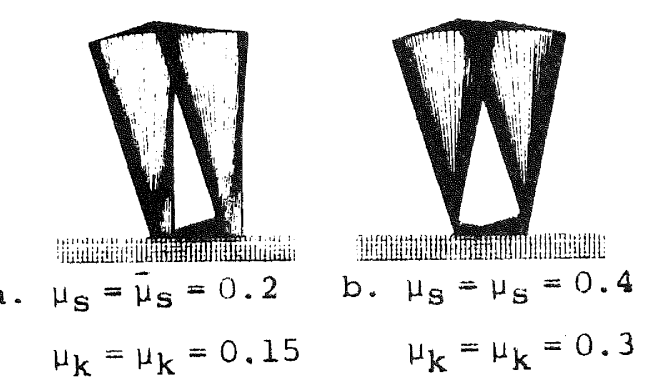

Eig.4 Simulations of Free Rocking

Effects of Coefs. of Friction -
$\left(\mathrm{b} / \mathrm{h}=1 / 3, \mathrm{~b}=5 \mathrm{~cm}, \mathrm{e}_{\mathrm{x}}=-1.0, \mathrm{e}_{\mathrm{y}}=0.0\right)$
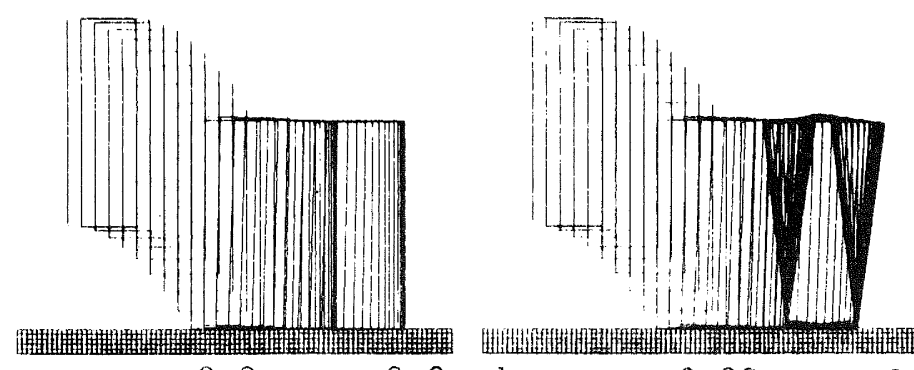

a. $e_{x}=-0.9, e_{y}=0.2$ b. $e_{x}=-0.89, e_{y}=0.2$

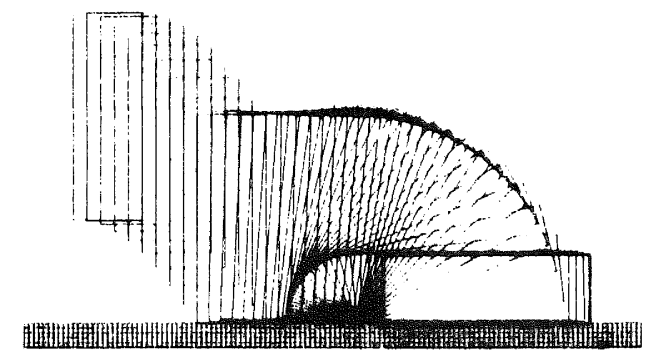

c. $e_{x}=-0.55, e_{y}=0.2$

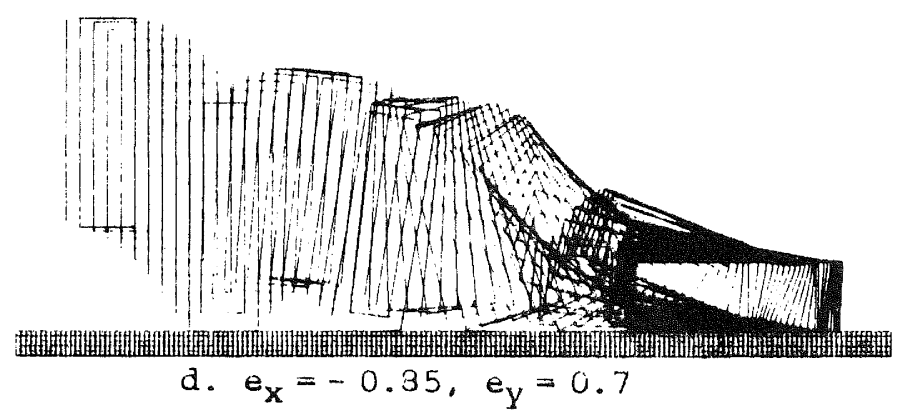

Fig.5 Simulations of Motions after Translation Jump $\left(\mathrm{b} / \mathrm{h}=1 / 3, \mathrm{~b}=5 \mathrm{~cm}, \mu_{\mathrm{S}}=\bar{\mu}_{\mathrm{s}}=0.4, \mu_{\mathrm{k}}=\bar{\mu}_{\mathrm{k}}=0.3\right.$, initial values; $\dot{x}=100 \mathrm{~cm} / \mathrm{sec}, y=15 \mathrm{~cm}, \dot{y}=0$ ) 
Equilibrating the above two forumlae, and rearranging, yields

$\omega^{2}=\frac{2 g r}{i^{2}+r^{2}}(1-\cos \alpha)$

The body undergoes the horizontal translation motion with the velocity $v$ and the motion suddenly shifts to rotation about the base edge. Assuming the conservation of angular momentum, the following relationship is obtained.

$v h=\left(i^{2}+r^{2}\right) \omega$ or $\omega=\frac{v h}{i^{2}+r^{2}}$

Substituting this into Eq. (7) yields

$v^{2}=\frac{2 g r}{h^{2}}\left(i^{2}+r^{2}\right)(1-\cos \alpha)$

$=\frac{2 g}{r}\left(i^{2}+r^{2}\right) \frac{1-\cos \alpha}{\cos ^{2} \alpha}$

In the case of a rectangular column

$i^{2}+r^{2}=\frac{4}{3} r^{2}$

Then, Eq. (9) becomes

$v^{2}=\frac{8 g r}{3} \cdot \frac{1-\cos \alpha}{\cos ^{2} \alpha}$

This is the horizontal velocity of a shock necessary to overturn a rectangular column. Milne (10) suggested that this relationship was derived by Mallet (Though Milne discussed this as the case of a cylindrical column). If $\alpha$ is small, $\cos \alpha \simeq 1$ and $(1-\cos \alpha) \simeq \alpha^{2} / 2$. Therefore Eq. (10) becomes

$$
v^{2}=\frac{4 g r}{3} \quad \alpha^{2}=\frac{4 g-b}{3} \alpha
$$

This is also obtained from Eq. (4), providing $a \cdot t_{0}=v$ and $t_{0} \rightarrow 0$.

Effects of Displacement:

If the duration of the shock is short, the body is not overturned even by a considerably larger acceleration than that given by West's formula. Therefore, Omori(5) analysed this fact as follows: If the period of input excitations is very short, the body rotates around its center of percussion and the horizontal displacement or twice of the amplitude $2 d$ to overturn the body is given by

$2 a=\frac{b\left(i^{2}+r^{2}\right)}{h^{2}}$

In the case of a rectangular column, this equation becomes

$2 d=\frac{4 r^{2}}{3 h^{2}} b$

The applicability of this equation has not been verified.

From the aforementioned discussion it should be noted that the criteria for overturning cannot be expressed only by the acceleration of excitations. Therefore, other effects, e.g. the effects of the period velocity, displacement, etc., should be taken into account.
OVERTURNING BY SINUSOIDAL EXCITATIONS:

\author{
Experiments on Frequency, Sweep \\ Tests Using a Shaking Table(20):
}

In order to study the conditions for the overturning of bodies, experiments on frequency sweep tests were conducted, using a shaking table in the Building Research Institute which could be driven horizontally

(See Table l). In the experi ments on frequency sweep tests the acceleration, velocity or displacement amplitude was kept constant, gradually shifting the frequency, and the conditions when the body overturned were measured. Test specimens were rectangular columns of various sizes and materials (See Table 2). They were placed on a $5 \mathrm{~cm}$ thick granite board which was mounted on the shaking table. In some cases, the granite board was covered by a $0.3 \mathrm{~cm}$ thick vinyl resin sheet, to change the coefficients of friction and restitution coefficients (See Tables 3 and 4 ).

Typical experimental results of the overturning of bodies by the frequency sweep tests are shown in Figs. 6 and 7. In these figures the ordinate is the normalized acceleration which is defined as the acceleration amplitude divided by the horizontal acceleration " $a$ " necessary to initiate rocking motion of the body, i.e. West's formula of Eq. (1); and the abscissa is the normalized velocity which is defined as the velocity amplitude divided by the velocity $v$ necessary to overturn the body by a single horizontal shock, i.e. $\mathrm{Eq}$. (9). It is found that the results in these figures are not affected much by the sizes and materials of the test specimens and by the materials of the floor.

Simulations of Frequency Sweep Tests:

Simulations of frequency sweep tests were conducted with or without vertical excitations, using the computer simulation program explained in the previous section. Carrying out series of frequency sweep simulation tests, it is found that the results are not affected much by the parameters involved; i.e. b, $h, \mu_{s}, \bar{\mu}_{s}$, $\mu_{\mathrm{k}}, \bar{\mu}_{\mathrm{k}}, \mathrm{e}_{\mathrm{x}}, \mathrm{e}_{\mathrm{y}}, \Delta t$, the duration of input excitations, the magnitude of vertical excitations, and the phase difference between horizontal and vertical excitations. Typical simulated results of overturning are shown in Figs. $8-10$.

Proposal of Criteria for Overturning:

Summarizing the results in the previous sections, Fig. 11 is obtained to show the overturning conditions produced by the frequency sweep tests. In Fig. 11, there are three kinds of overturning (see Fig. 12). In the case of constant acceleration amplitude sweep tests the body usually initiates inverse phase rocking motion, and overturning from this inverse phase rocking (See Fig. 13) occurs when the input excitations reach curve a in Fig. 11. But if the body initiates subharmonic rocking motion, the overturning from subharmonic rocking (See Fig. 14) occurs at curve $b$ in Fig. 11. It is difficult to tel1 the conditions that make the body undergo the 


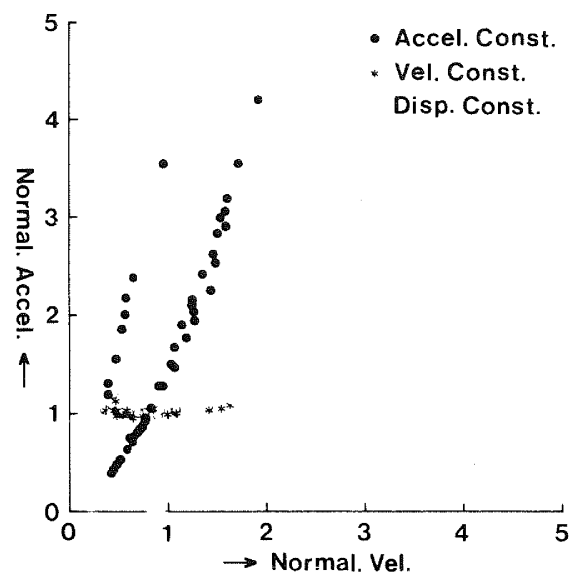

Fig.6 Experimental Results of Overturning (Specimen: G4)

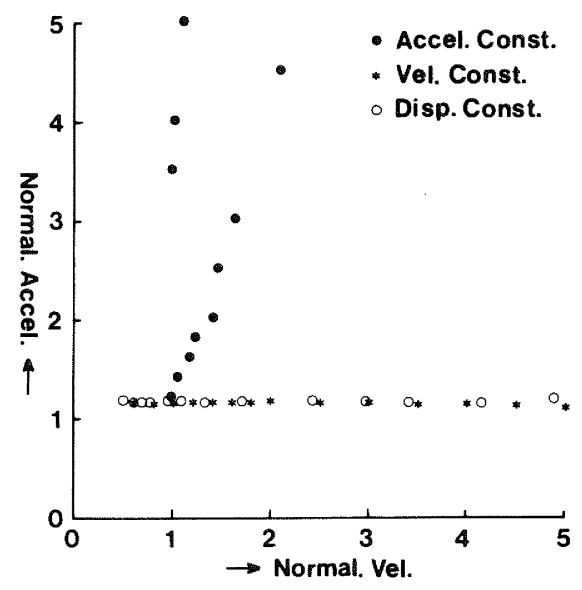

Fig.8 Simulations of Overturning $(\mathrm{b} \times \mathrm{h}=10 \times 50 \mathrm{~cm})$

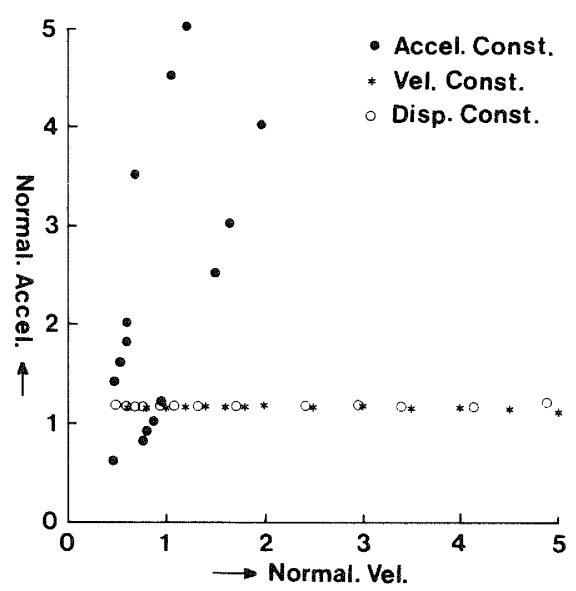

Fig.10 Simulations of Overturning $(\mathrm{b} \times \mathrm{h}=2.5 \times 7.5 \mathrm{~cm}$, Initial angular disp. $=0.1 \alpha$ )

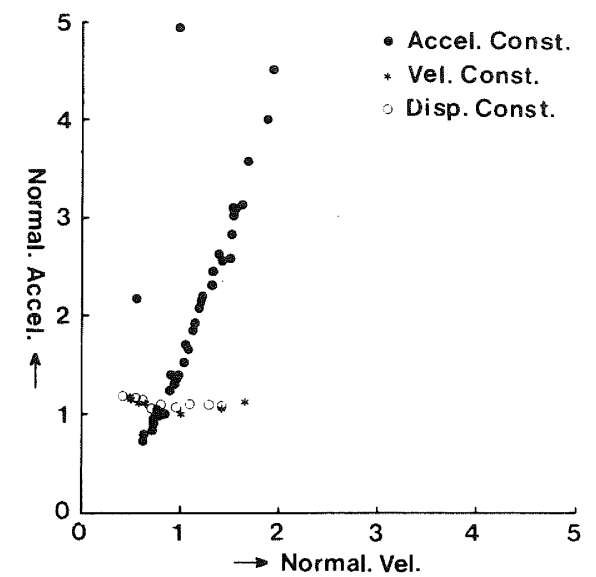

Fig.7 Experimental Results of Overturning (Specimen: W2)

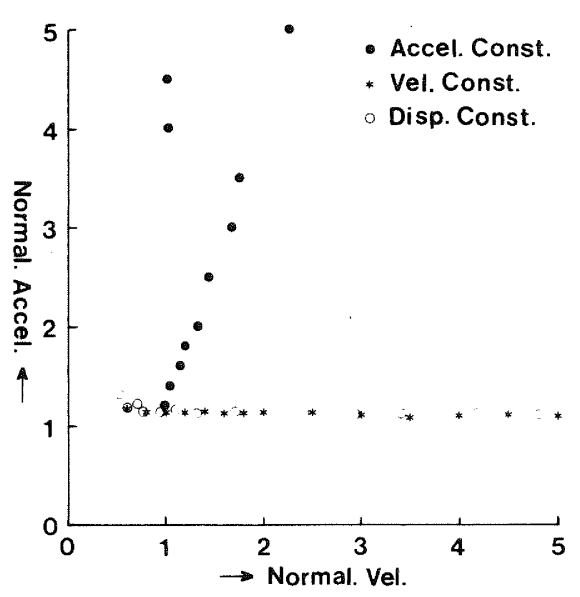

Fig.9 Simulation of Overturning $(\mathrm{b} \times \mathrm{h}=2.5 \times 7.5 \mathrm{~cm})$

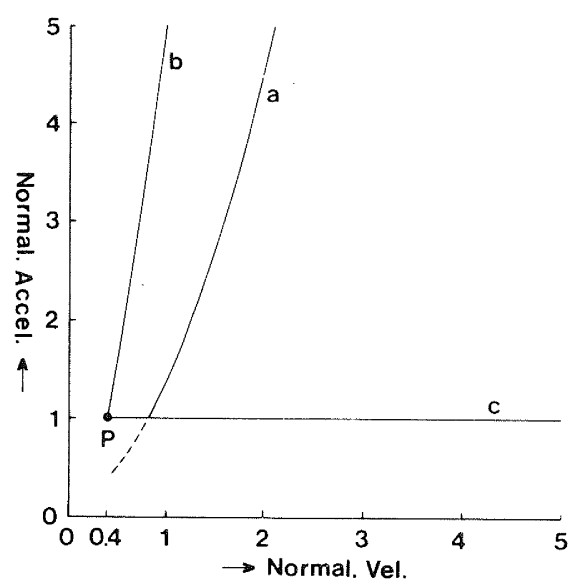

Fig.ll Boundaries of Overturning 
inverse phase or subharmonic rocking motion. In the case of constant velocity or displacement amplitude sweep tests, the body repeats its "in phase" rocking motion only a few times and overturning from in phase rocking (see Figs. 15 and 16) occurs at line c in Fig. 11.

A discrepancy between the experiments (See Figs. 6 and 7) and simulations (See Figs. 8 and 9) is that the overturning can occur at the lower acceleration than the value given by West's formula of Eq. (1) in the case of experiments (see the dotted curve in Fig. 11). In order to study this phenomenon, the frequency sweep simulation tests have been conducted with small initial angular displacements. The simulated results are shown in Fig. I0 which is much more similar to experimental results. Then, it is found that the body can be overturned by an acceleration which is less than one unit of the normalized acceleration, if some shocks initiate the rocking motion of the body.

From the results of experiments and simulations in the previous sections, it is found that the lower limits of normalized acceleration and velocity necessary to overturn the body (point $P$ in Fig. 11) are not affected much by $b / h$, size of the body, $\mu_{s}, \bar{\mu}_{s^{\prime}} \mu_{k}, \bar{\mu}_{k^{\prime}} e_{x^{\prime}} e_{y}$ or by the existence of vertical excitations. The dotted curve in Fig. 11 can be neglected, because the shocks which initiate the rocking motion of the body should be more than one unit of normalized acceleration. Therefore, we can estimate criteria to overturn a body as follows: The acceleration amplitude $a_{0}$, which is the lower

limit of the maximum horizontal acceleration to overturn the body, is approximately equal to the normalized acceleration.

$$
a_{0} \simeq \frac{b}{h} g=\frac{B}{H} g
$$

where $B$ and $H$ are the breadth and height of a rectangular body, respectively. The velocity amplitude $\mathrm{v}_{0^{\prime}}$ which is the lower limit of the maximum velocity to overturn the body, is approximately 0.4 times the normalized velocity.

$v_{0} \simeq 0.4 \sqrt{\frac{2 g}{r}\left(i^{2}+r^{2}\right) \frac{1-\cos \alpha}{\cos ^{2} \alpha}}$

In the case of a rectangular body,

$\mathrm{v}_{0} \simeq 0.4 \sqrt{\frac{8 \mathrm{gr}}{3} \cdot \frac{1-\cos \alpha}{\cos ^{2} \alpha}}$

If $\alpha$ is small,

$v_{0} \simeq 0.4 \sqrt{\frac{4 g b}{3} \alpha}$

$\simeq 10 \frac{\mathrm{B}}{\sqrt{\mathrm{H}}}$ (unit: $\mathrm{cm}, \mathrm{sec}$ )

Considering the displacement amplitude, it is greater than the value that makes the normalized acceleration equal to 1.0 and the normalized velocity equal to 0.4. Then using the relationship of $v_{0}{ }^{2}=a_{0} d_{0}$, the displacement amplitude $d_{0}$ which is the lower limit of the maximum displacement necessary to overturn the body, is given by

$\mathrm{d}_{0}=\frac{\mathrm{v}_{0}^{2}}{\mathrm{a}_{0}}$

In the case of a rectangular body and

if $\alpha$ is small,

$\mathrm{d}_{0} \simeq \frac{\mathrm{B}}{10}$

Using the criteria to overturn the body given by Eqs. (14), (16) and (18), the diagram to estimate the lower limits of the maximum acceleration, velocity and displacement from the size of an overturned homogeneous rectangular body can be made as shown in Fig. 17. These criteria for overturning have been derived from the results by sinusoidal excitations, but they also may be applicable in the case of earthquake excitations as shown in the next section.

The period $T_{C}$ at the point $P$ in Fig. 11 is

$\mathrm{T}_{\mathrm{C}}=2 \pi \frac{\mathrm{a}_{\mathrm{O}}}{\mathrm{v}_{\mathrm{O}}}=2 \pi \frac{\mathrm{v}_{\mathrm{O}}}{\mathrm{d}_{\mathrm{O}}}$

In the case of a rectangular body and if $\alpha$ is small, Eq. (20) becomes

$\mathrm{T}_{\mathrm{C}} \simeq \frac{\sqrt{\mathrm{H}}}{16}$ (unit: $\mathrm{cm}, \mathrm{sec}$ )

If the period of the input excitations is shorter than this, the acceleration must be much larger than the value given by Eq. (14) in order to overturn the body. Therefore, Eq. (21) can be the empirical formula for the critical period of Mochizuki and Kobayashi.(15) Actually Eq. (21) shows a very good agreement with the simulated results by Mochizuki and Kobayashi.

\section{APPLICATION OF THE CRITERIA TO EARTHQUAKE EXCITATIONS :}

Motions of a rectangular body subjected to recorded earthquake horizontal excitations with or without the vertical components were simulated, considering various sizes of the body. Table 5 lists the maximum accelerations, velocities and displacements of these excitations.

The simulated results of overturning are shown in Figs. 18-20; where the abscissa and coordinate are the height $\mathrm{H}$ and the height breadth ratio $\mathrm{H} / \mathrm{B}$ of the rectangular bodies, respectively. In these figures, the acceleration and velocity criteria for overturning -- i.e. Eqs. (14 and (16), respectively -are also indicated; substituting the maximum accelerations and velocities of the earthquake excitations. From these figures, it can be seen that the criteria derived in the previous section are also applicable to earthquake excitations as summarized in Fig. 21. In this figure, $A$ is the region of neither rocking nor overturning, $B$ is the region of rocking but no overturning, and $\mathrm{C}$ is the region of rocking and probable overturning. The 


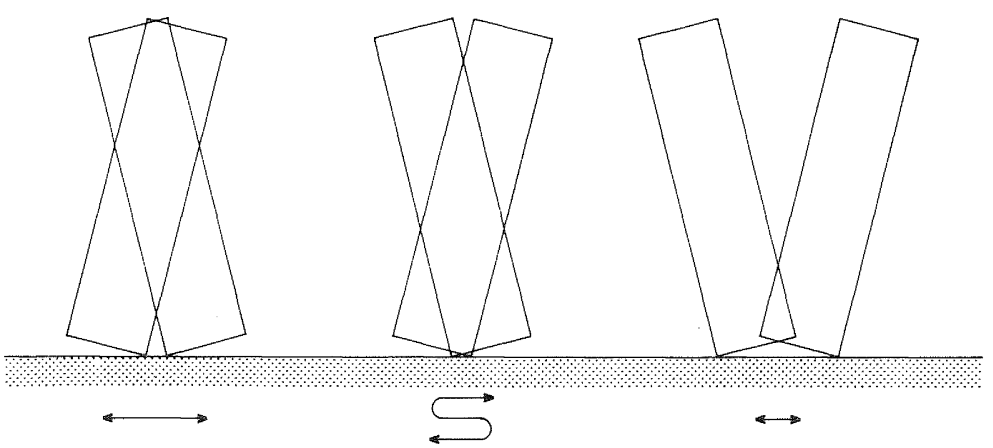
a. Inverse
phase
b. Subharmonic rocking
C. In phase rocking rocking

Fig.12 Three Kinds of Rocking Motions before Overturning

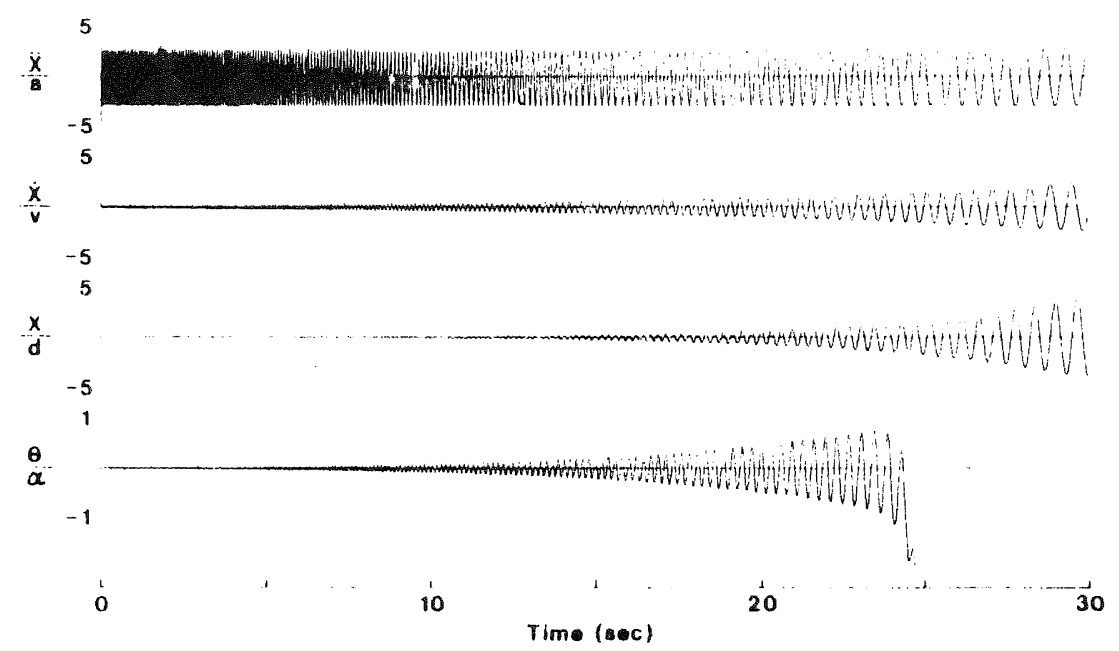

Fig.13 Overturning by Constant Acceleration Amplitude Frequency Sweep Tests (Overturning from Inverse Phase Rocking)

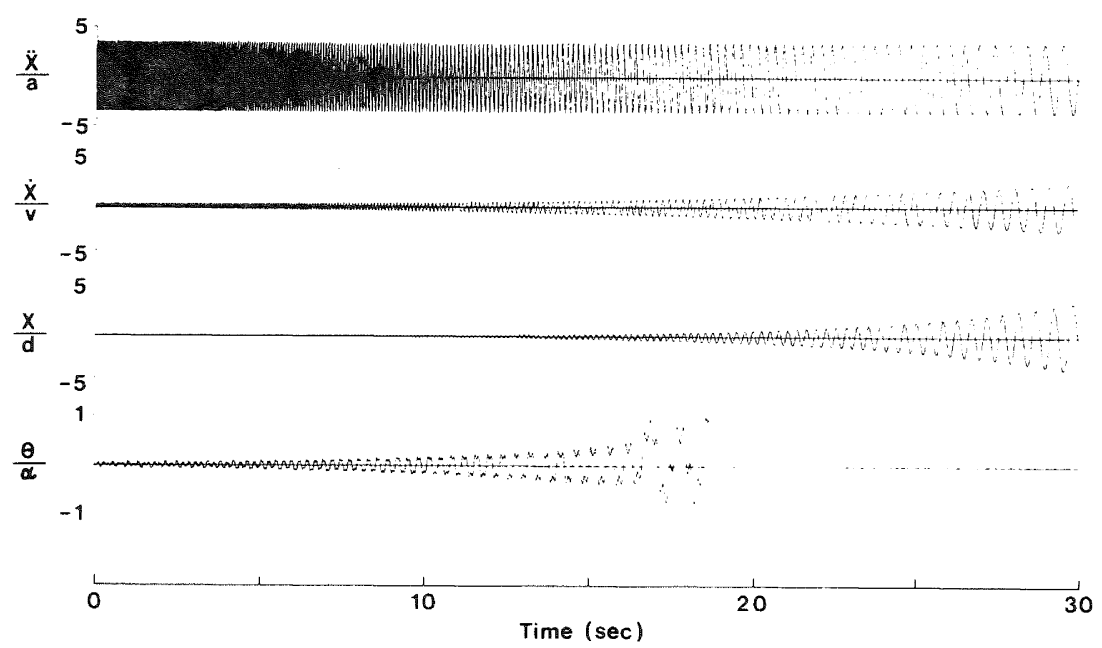

Fig.14 Overturning by Constant Acceleration Amplitude Frequency Sweep Tests (Overturning from Subharmonic Rocking) 
behaviour of the bodies in region $C$ is highly irregular, i.e. the taller bodies are sometimes more stable than shorter ones of the same breadth. The effect of vertical excitations is small and it does not always increase the probability of overturning. The effect of $\mu_{s}, \bar{\mu}_{s}, \mu_{k}, \bar{\mu}_{k}, e_{x}, e_{y}$ and $\Delta t$ are also small. As to the bodies in region $C$, the smaller ones have the higher probability of overturning.

These comments are drawn from simulations using several different earthquake excitations. In order to study in more detail the behaviour of the body subjected to random inputs like earthquake excitations, and to estimate the intensity of the excitations from the size of the body overturned, statistical considerations should be introduced, as suggested by YIM, C.S. et al. (21)

Actually, all the bodies overturned are in region C -- or very close to -of Fig. 21. Therefore, from the size of the body overturned, we can conclude that the maximum horizontal acceleration and velocity must have been greater than the values given by Eqs. (14) and (15), respectively. Considering the displacement criterion of Eq. (18), it seems that the criterion is too conservative, though it certainly gives the lower limit of the maximum horizontal displacement due to the earthquake excitations.

\section{CONCLUSIONS :}

The computer simulation studies indicate the following:

The coefficient of friction is one of the most influential factors affecting rocking motion. The coefficient of friction must be greater than $b / h$, in order for the body to continue rocking motions.

(2) The motion after impact from translation jump is greatly influenced by the normal and tangent restitution coefficients.

Criteria for overturning are studied and the following are concluded:

(3) Simulations and experiments of frequency sweep tests show that, in order to overturn a body, both the horizontal acceleration and the velocity of the floor must be greater than certain levels.

(4) These levels provide the minimum criteria for overturning the body, i.e. 1.0 times the acceleration given by West's formula and 0.4 times the velocity of the shock to overturn the body. Therefore it is possible to estimate the lower limits of the maximum horizontal acceleration $a_{0}$, velocity $v_{0}$ and displacement $d_{0}$ of the input excitations from the size of the body overturned.

In the case of a slender rectangular body whose breadth and height are $B$ and $H$, respectively; they are

$$
\begin{aligned}
& a_{0} \simeq \frac{B}{H} g \quad\left(g: \begin{array}{l}
\text { gravitational } \\
\text { acceleration })
\end{array}\right. \\
& v_{0} \simeq 10 \frac{B}{\sqrt{H}} \text { (unit: } \mathrm{cm}, \mathrm{sec} \text { ) } \\
& d_{0} \simeq \frac{B}{10}
\end{aligned}
$$

(5) Simulations of actual earthquake excitations show that the criteria are also applicable to earthquake excitations. Therefore, we can estimate the lower limits of the maximum horizontal acceleration and velocity of the input excitations from the size of the body overturned.

\section{ACKNOWLEDGEMENT :}

The author wishes to express deepest appreciation to Prof. Takuji Shibata of Hokkaido Univ., Prof. Toshihiro Irie of Hokkaido Univ., Prof. Yutaka Matsushima of Tsukuba Univ., Prof. Michio Otsuka of Kyushu Univ. and Dr Makato Watabe of I.I.S.E.E., B.R.I. for their valuable advice and encouragement; to Dr Tetsuo Kubo of I.I.S.E.E., B.R.I. for providing corrected time histories of recorded earthquake excitations; to Miss Sumiko Endo of I.I.S.E.E., B.R.I. for typing the manuscript; and to Mr Nobuyoshi Yamaguchi of I.I.S.E.E., B.R.I. for computer and experimental work.

\section{BIBLIOGRAPHY :}

Milne, J., "Experiments in Observational Seismology ", Transactions of the Seismological Society of Japan, Vol. 3, Jan. to Dec. (1881).

Perry, J., "Note on the Rocking of a Column "Transactions of the Seismological Society of Japan, Vol. 3., Jan. to Dec. (1881).

Ishiyama, Y., "Review and Discussion on Overturning of Bodies by Earthquake Motions ", BRI Research Paper No. 85, Building Research Institute, Ministry of Construction, June (1980).

Omori, F., "Research on Fracturing and Overturning of Columns (Report on Seismic Experiments by shaking Table) (in Japanese) ", Publication of the Earthquake Investigation Committee, No. 28, Sept. (1899).

Omori, F., "On the Overturning and Sliding of Columns (in Japanese)", Publication of the Earthquake Investigation Committee, No. 32 , July, (1900).

Ikegami, R. and Kishinouye, F. "A Study on the Overturning of Rectangular Columns in the case of the Nankai Earthquake on December 21, 1946", Bulletin of the Earthquake Research Institute, Tokyo University, Vol. 25, Jan. to Dec. (1947).

Ikegami, R. and Kishinouye, F., "The Acceleration of Earthquake Motion Deduced from Overturning of the Gravestones in Case of Imaichi Earthquake on Dec. 26, 1949 ", 


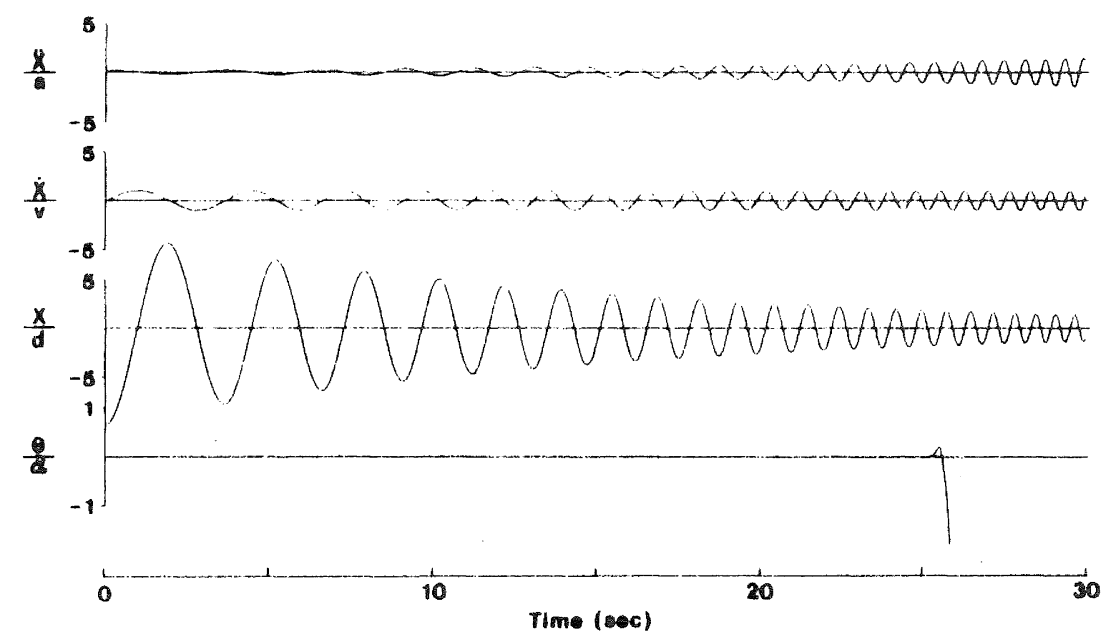

Fig.15 Overturning by Constant Velocity Amplitude Frequency Sweep Tests (Overturning from In Phase Rocking)

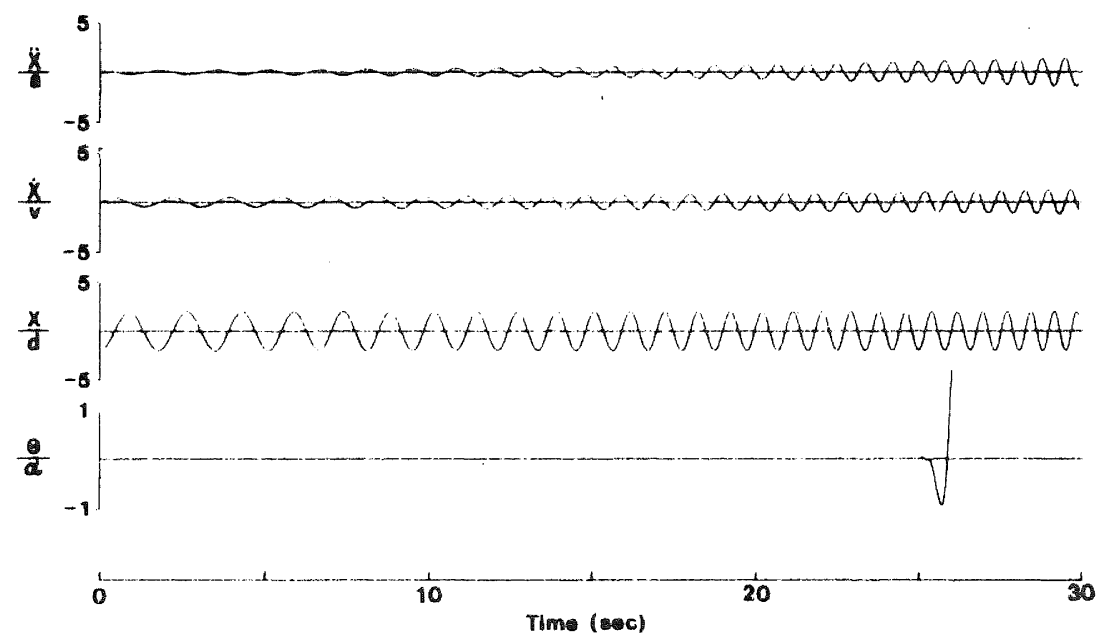

Fig.16 Overturning by Constant Displacement Amplitude Frequency Sweep Tests (Overturning from In Phase Rocking)

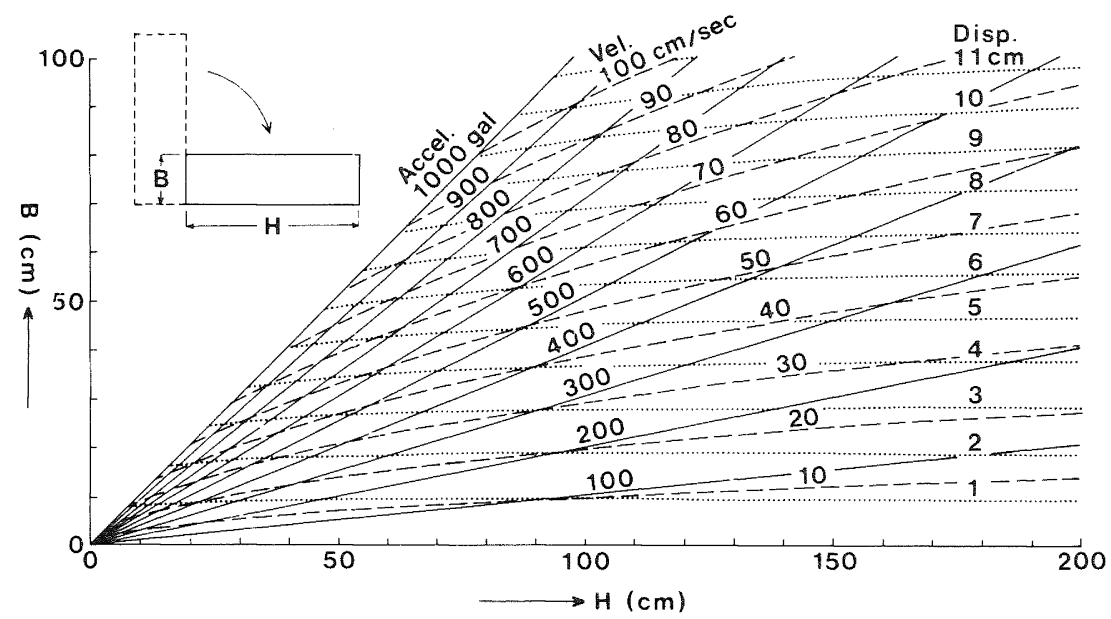

Fig.17 Lower Limits of Acceleration, Velocity and Displacement to Overturn the Homegeneous Rectangular Bodies 
Bulletin of the Earthquake Research Institute, Tokyo University, Vol. 28, Jan. to June (1950).

(8) Ishiyama, Y., Matsushima, Y., Yamazaki, Y. and Nakata, S. "Vibration Test and Theoretical Consideration on Overturning of Furniture During Earthquakes (in Japanese) "r Reports of the Annual Meeting 1978, The Architectural Institute of Japan, Sept. (1978).

Aslam, M., Godden, W.G. and Scalise D.T." "Earthquake Rocking Response of Rigid Bodies ", Journal of the Structural Division, Proceedings of the American Society of Civil Engineers, Vol. 106, No. ST2, Feb. (1980).

(10) Milne, J., "Seismic Experiments ". Transactions of the Seismological Society of Japan, Vol. 8, (1885).

(11) Mononobe, O., "Consideration on Vertical Motions during Earthquakes and Miscellaneous Notes on Dynamics (in Japanese) ", Journal of the Civil Engineering Society, Vol. 10, No. 5, Oct. (1924).

Kimura, H. and Iida, K., "On Rocking of Rectangular Columns (I) (in Japanese) ", Zishin (Journal of the Seismological Society of Japan), Vol. 6, No. 3, March (1934).

(13) Kimura, H. and Iida, K., "On Rocking of Rectangular Columns (II) (in Japanese) ", Zishin (Journal of the Seismological Society of Japan), Vol. 6, No. 4, Apr. (1934).

(14) Ohtsuki, Y. and Kanai, K., "Earthquake Resistant Design (in Japanese) ", Corona-sha, March (1961).

(15) Mochizuki, T. and Kobayashi, K., "A Study on Acceleration of Earthquake Motion Deduced from the Movement of Column - An Analysis on the Movement of Column (in Japanese) ", Transactions of the Architectural Institute of Japan, No. 248, Oct. (1976).

(16) Ishiyama, Y., "Motions of Rigid Bodies in Response to Earthquake Excitations - Equations of Motions and Computer simulation - ", Transactions of the Architectural Institute of Japan, No. 314, Apr. (1982).

(17) Ishiyama, Y., "Motions of Rigid Bodies and Criteria for Overturning by Earthquake Excitations ", Earthquake Engineering and Structural Dynamics, Vol. 10, No. 5, sept.-Oct. (1982).

(18) Kirkpatrick, P., "Seismic Measurements by the Overthrow of Columns", Bulletin of the Seismological Society of America, Vol. 17, No. 2, (1927).

(19) Housner, G.W., "The Behaviour of Inverted Pendulum Structures During Earthquakes ", Bulletin of the
Seismological Society of America, Vol. 53, No. 2, Feb. (1963).

Ishiyama, Y., "Criteria for Overturning of Bodies by Earthquake Excitations " Transactions of the Architectural Institute of Japan, No. 317, July (1982).

(21) Yim, D.S., Chopra, A.K. and Penzien, J., "Rocking Response of Rigid Blocks to Earthquakes", Report No. UCB/EERC-80/02 Earthquake Engineering Research Center, University of California, Berkeley, California, Jan. (1980).

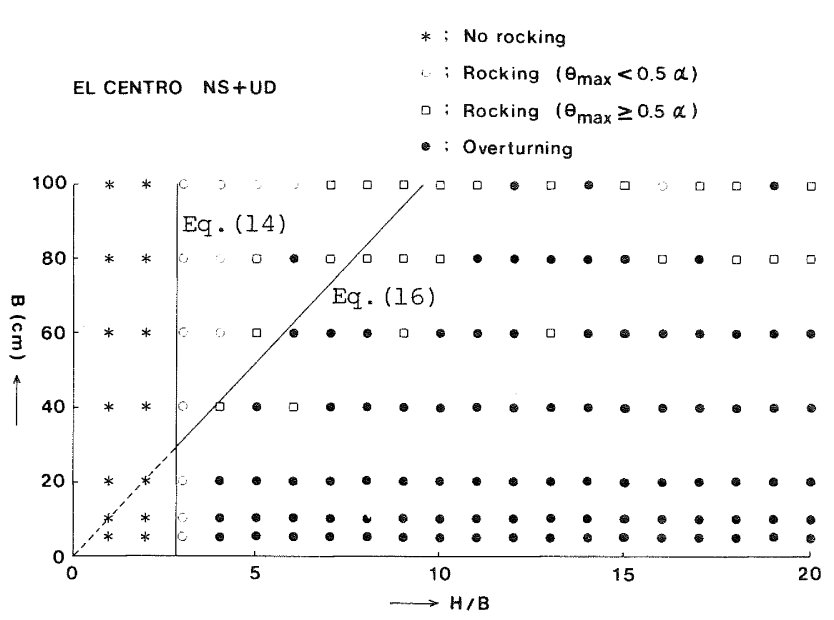

Fig.18 Motions of Bodies by EL CENTRO Earthquake (NS + UD component)

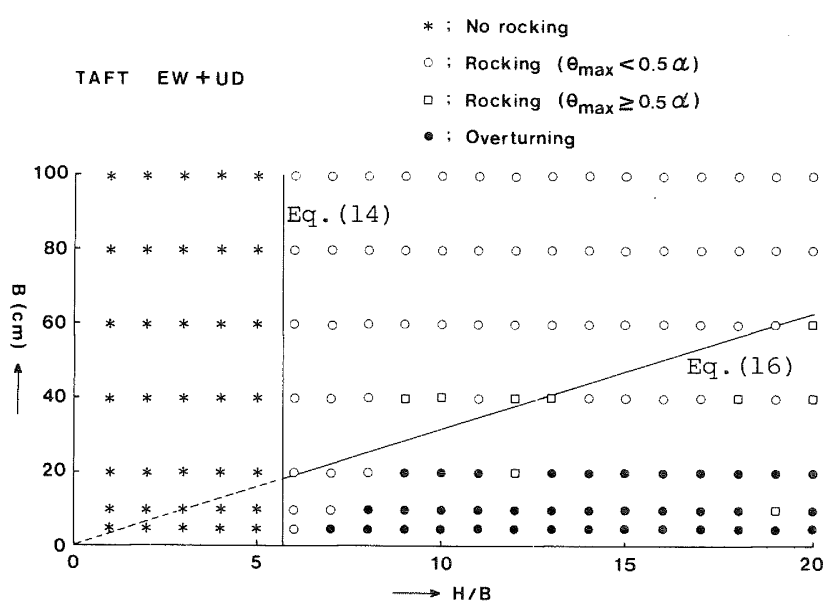

Fig.19 Motions of Bodies by TAFT Earthquake (EV + UD component) 
TABLE 1: SPECIFICATIONS OF A SHAKING TABLE

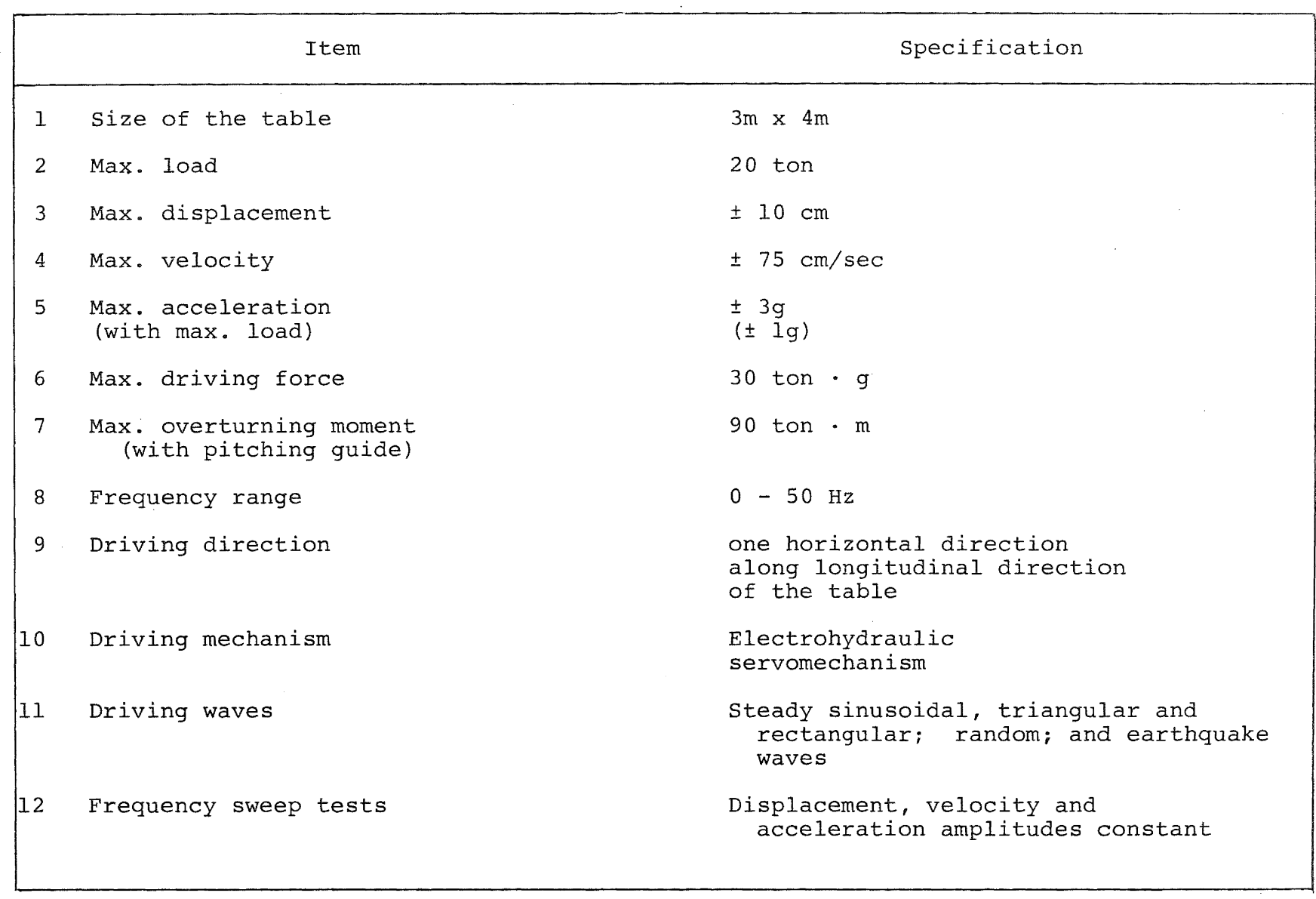

TABLE 2: TEST SPECIMENS

\begin{tabular}{|c|c|c|c|c|c|c|c|c|}
\hline Specimen & Material & *1 & $\begin{array}{l}\mathrm{B} \\
(\mathrm{cm})\end{array}$ & $\begin{array}{l}\mathrm{H} \\
(\mathrm{cm})\end{array}$ & $\begin{array}{l}\mathrm{D} \\
(\mathrm{cm})\end{array}$ & $\frac{\mathrm{B}}{\mathrm{H}}$ & $\begin{array}{l}\text { Weight } \\
(\text { gr.) }\end{array}$ & ${ }^{i} \circ \begin{array}{c}* 2 \\
(\mathrm{~cm})\end{array}$ \\
\hline $\begin{array}{l}\text { A1 } \\
\text { A2 } \\
\text { A3 } \\
\text { A4 }\end{array}$ & acrylic resin & B & $\begin{array}{r}5.0 \\
5.0 \\
10.0 \\
10.0\end{array}$ & $\begin{array}{l}15.0 \\
25.0 \\
30.0 \\
40.0\end{array}$ & $\begin{array}{r}7.5 \\
7.5 \\
15.0 \\
15.0\end{array}$ & $\begin{array}{l}1 / 3 \\
1 / 5 \\
1 / 3 \\
1 / 4\end{array}$ & $\begin{array}{r}300 \\
450 \\
1270 \\
1620\end{array}$ & $\begin{array}{r}9.33 \\
14.94 \\
18.79 \\
24.35\end{array}$ \\
\hline $\begin{array}{l}\mathrm{GI} \\
\mathrm{G} 2 \\
\mathrm{G} 3 \\
\mathrm{G} 4\end{array}$ & hard rubber & $\mathrm{s}$ & $\begin{array}{l}4.95 \\
5.0 \\
5.0 \\
5.0\end{array}$ & $\begin{array}{l}14.9 \\
19.9 \\
25.0 \\
25.0\end{array}$ & $\begin{array}{l}7.5 \\
7.5 \\
7.5 \\
7.45\end{array}$ & $\begin{array}{l}1 / 3 \\
1 / 4 \\
1 / 5 \\
1 / 5\end{array}$ & $\begin{array}{r}740 \\
975 \\
1225 \\
1220\end{array}$ & $\begin{array}{r}9.06 \\
11.85 \\
14.72 \\
14.72\end{array}$ \\
\hline $\begin{array}{l}\text { P1 } \\
\text { P2 } \\
\text { P3 } \\
\text { P4 }\end{array}$ & plastic & $\mathrm{S}$ & $\begin{array}{l}5.0 \\
5.0 \\
4.95 \\
4.9\end{array}$ & $\begin{array}{l}14.95 \\
19.95 \\
24.8 \\
24.8\end{array}$ & $\begin{array}{l}7.45 \\
7.45 \\
7.45 \\
7.45\end{array}$ & $\begin{array}{l}1 / 3 \\
1 / 4 \\
1 / 5 \\
1 / 5\end{array}$ & $\begin{array}{r}665 \\
970 \\
1200 \\
1180\end{array}$ & $\begin{array}{r}9.10 \\
11.87 \\
14.60 \\
14.60\end{array}$ \\
\hline $\begin{array}{l}\mathrm{W} 1 \\
\mathrm{~W} 2\end{array}$ & wood & $\mathrm{s}$ & $\begin{array}{l}5.0 \\
5.0\end{array}$ & $\begin{array}{l}15.0 \\
25.0\end{array}$ & $\begin{array}{l}7.5 \\
7.5\end{array}$ & $\begin{array}{l}1 / 3 \\
1 / 5\end{array}$ & $\begin{array}{l}360 \\
620\end{array}$ & $\begin{array}{r}9.13 \\
14.72\end{array}$ \\
\hline
\end{tabular}

*1: Shape, $\mathrm{B}=$ Rectangular box, $\mathrm{S}=$ Rectangular solid column

*2: Radius of gyration about the base edge 


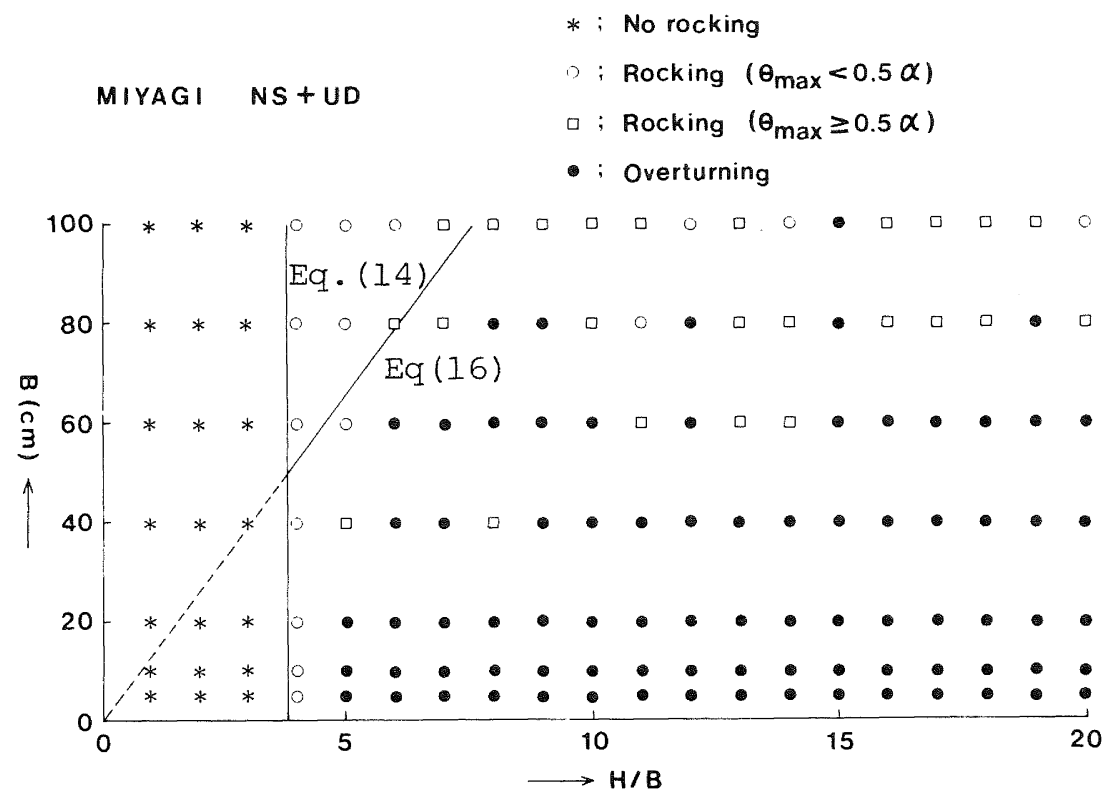

Fig.20 Motions of Bodies by MIYAGI-KEN-OKI Earthquake (NS + UD component)

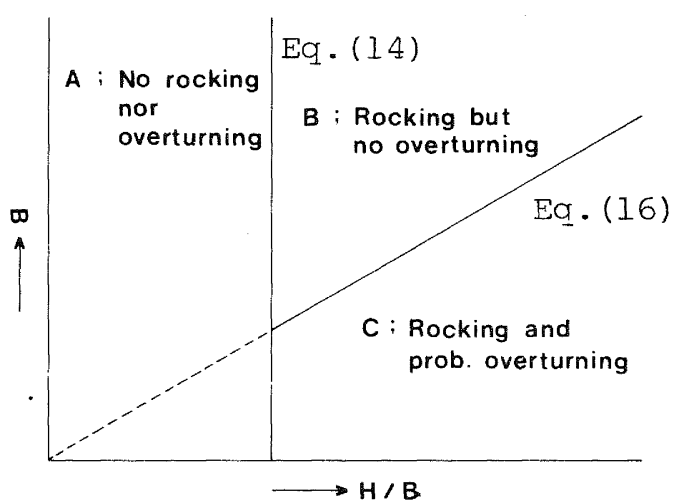

(a)

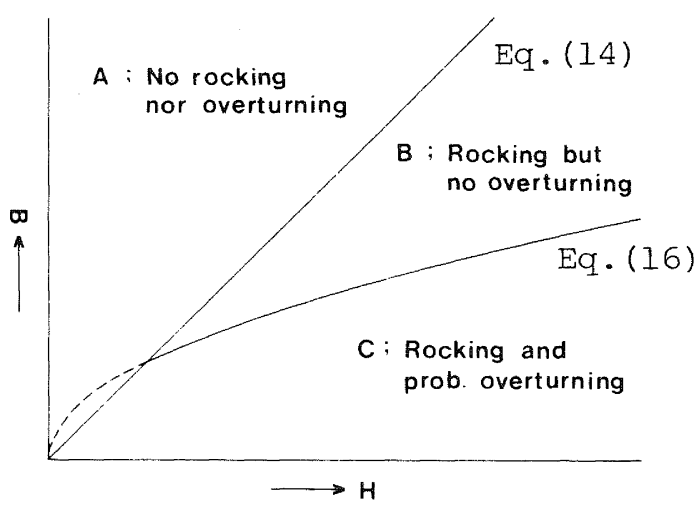

(b)

Fig.21 Motions of Bodies by Earthquake Excitations 
TABLE 3: COEFFICIENTS OF FRICTION

\begin{tabular}{|lccccc|}
\hline $\begin{array}{l}\text { Material } \\
\text { of floor }\end{array}$ & $\begin{array}{c}\text { Coefs. of } \\
\text { friction }\end{array}$ & $\begin{array}{c}\text { Acrylic } \\
\text { resin }\end{array}$ & $\begin{array}{c}\text { Mard } \\
\text { rubber }\end{array}$ & wood \\
\hline \multirow{2}{*}{$\begin{array}{l}\text { Vinyl } \\
\text { resin }\end{array}$} & $\mu_{\mathrm{s}}$ & 0.73 & 0.96 & 0.74 & 0.81 \\
\hline & $\mu_{\mathrm{k}}$ & 0.42 & 0.47 & 0.35 & 0.49 \\
Granite & $\mu_{\mathrm{s}}$ & 0.37 & 0.81 & 0.44 & 0.35 \\
& $\mu_{\mathrm{k}}$ & 0.40 & 0.68 & 0.54 & 0.40 \\
\hline
\end{tabular}

TABLE 4: NORMAL RESTITUTION COEFFICIENTS $e_{y}$

\begin{tabular}{|lccc|}
\hline \multirow{2}{*}{$\begin{array}{l}\text { Material } \\
\text { of floor }\end{array}$} & \multicolumn{3}{c|}{ Material of balls } \\
\cline { 2 - 4 } & $\begin{array}{c}\text { Hard } \\
\text { rubber }\end{array}$ & Plastic & Wood \\
\hline Vinyl resin & 0.86 & 0.83 & 0.59 \\
Granite & 0.86 & 0.90 & 0.53 \\
\hline
\end{tabular}

TABLE 5: MAXIMUM VALUES OF RECORDED EARTHQUAKE EXCITATIONS USED FOR THE SIMULATIONS

\begin{tabular}{|c|c|c|c|c|}
\hline $\begin{array}{c}\text { Eârthquake } \\
\text { (Date) }\end{array}$ & Component & $\begin{array}{l}\text { Max. accel. } \\
\text { (gal) }\end{array}$ & $\begin{array}{l}\text { Max. vel. } \\
(\mathrm{cm} / \mathrm{sec})\end{array}$ & Max. $\underset{(\mathrm{cm})}{\text { displace. }}$ \\
\hline $\begin{array}{l}\text { E1 Centro } \\
(\text { May 18, 1940) }\end{array}$ & $\begin{array}{l}\text { NS } \\
\text { EW } \\
\text { UD }\end{array}$ & $\begin{array}{l}341.7 \\
210.1 \\
206.3\end{array}$ & $\begin{array}{l}32.32 \\
36.47 \\
10.21\end{array}$ & $\begin{array}{r}10.86 \\
19.78 \\
5.55\end{array}$ \\
\hline $\begin{array}{l}\text { Taft } \\
\text { (July 21, 1952) }\end{array}$ & $\begin{array}{l}\text { NS } \\
\text { EW } \\
\text { UD }\end{array}$ & $\begin{array}{l}152.7 \\
175.9 \\
102.9\end{array}$ & $\begin{array}{r}15.72 \\
17.71 \\
6.67\end{array}$ & $\begin{array}{l}6.69 \\
9.15 \\
5.03\end{array}$ \\
\hline $\begin{array}{l}\text { Miyagi-Ken-Oki } \\
\text { (June } 12,1978 \text { ) }\end{array}$ & $\begin{array}{l}\text { NS } \\
\text { EW } \\
\text { UD }\end{array}$ & $\begin{array}{l}258.1 \\
203.4 \\
152.8\end{array}$ & $\begin{array}{l}36.27 \\
27.46 \\
12.00\end{array}$ & $\begin{array}{r}14.33 \\
9.81 \\
3.50\end{array}$ \\
\hline
\end{tabular}

